\title{
Government Policies, Implementation Leadership and Green Management Practices in an Emerging Economy
}

\author{
Rifat Kamasak, Ugur Yozgat, and Meltem Yavuz
}

\begin{abstract}
This study aims to investigate the effects of government practices and leadership activities on the way of implementing green management practices in firms. In order to address this aim, a survey was conducted on a sample of 153 firms which operate in the chemical and petrochemical industries in Turkey. The findings revealed that leadership activities contributed more than government policies on the adoption of green management practices of the firms. However, the combined effect of the government policies and leadership activities was the greatest on the adoption of green management practices.
\end{abstract}

Index Terms-Government policies, green management practices, implementation leadership, Turkey.

\section{BACKGROUND TO THE STUDY}

The concept of sustainable development has received growing recognition, but it is still a new idea with several unknowns for many firms and business executives especially in emerging economies. One of the most common cliché that constrains the integration of sustainable development principles into the strategic plans and measurement systems of firms at the desired level is that environmental concerns often inhibit business growth. Therefore, the argument of a trade-off between a healthy environment on the one hand and profitable firm growth on the other hand resulted to the lack of satisfactory implementation of green management activities as an important element of sustainable development in emerging economy firms. For example, Turkey which is considered as a big emerging economy still suffers from an economic development model that continues to harm natural resources and ignores habitats [1]. In line with the UN Report, in a research project that was conducted by the Economist Intelligence Unit and sponsored by Siemens in 2012 [2], Istanbul has taken the 25th place out of 30 cities (only better than Zagreb, Belgrade, Bucharest, Sofia and Kiev) in the European Green City Index. Similarly, according to a CDP report [3] published by $\mathrm{PwC}$ in September 2013, only 39 companies out of 410 included in the Istanbul Stock Exchange Index (BIST-100) disclosed their carbon emissions and climate change strategies.

However, a large body of research [4]-[6] that firms that

Manuscript received April 18, 2016; revised July 14, 2016.

Rifat Kamasak is with the Faculty of Commerce, Yeditepe University, Atasehir, Istanbul, 34755 Turkey (e-mail: rkamasak@yeditepe.edu.tr).

Ugur Yozgat is with the Faculty of Business Administration, Marmara University, Bahcelievler, Istanbul, 34180 Turkey (e-mail: uguryozgat@marmara.edu.tr).

Meltem Yavuz is with the Faculty of Transportation and Logistics, Istanbul University, Avcilar, Istanbul, 34320 Turkey (e-mail: meltem.yavuz@istanbul.edu.tr). endeavor to conduct sound green management practices (GMP) can improve organizational performance while preserving the natural environment. Moreover, several researchers [7]-[9] considered the adoption ability of GMP as a firm-level organizational capability that can lead to competitive advantage. Within this perspective, although GMP and sustainability-related principles have generally become beyond a voluntary social responsibility and have been integrated into the corporate strategic management processes, structures, cultures, systems and technologies of firms in developed countries, green issues are interpreted differently in emerging economies. Emerging economies show different market characteristics such as higher political risk, a relatively more dominant role of government in the economy and higher rate of volatility in financial markets and weaker institutional infrastructure compared to developed countries such as the US and the European Union (EU) countries [10], [11].

Since ethical business behaviors and practices are culturally and institutionally determined, green issues can be perceived differently in emerging economies where several unethical practices are easily tolerated by firms and local and government institutions [4], [12]. In developed countries, the focus is on environmental management and sustainability while rapid growth and profitability are paramount in emerging economies.

These conditions along with the environmental turbulence and uncertainty generally discourage firms to adopt GMP in emerging economies. Moreover, the government and legal mechanisms regarding green issues may be dysfunctionalized through unethical conducts as well. However, IMF statistics indicate that "emerging economies' share of business has risen steadily from just about $17 \%$ in the 1960 s to an average of $31 \%$ during the period of rapid global trade and financial integration that started in the mid-1980s and it reached to $42 \%$ in 2011" [13]. Although the average income per capita (i.e. GDP per capita) will still be significantly higher in the advanced economies than the emerging economies in 2050 [14], the global GDP contribution of emerging economies like Mexico and Indonesia are projected to be larger than the UK and France by 2030 while Turkey could become larger than Italy. Nigeria and Vietnam could be the fast growing large economies over the period to 2050 [15]. Emerging economies cannot be ignored since their economies will hold ever greater shares of global assets and wealth in the following years. The role of business in sustainability is unquestionable and emerging economies will play important roles in social development of the world as well as they do in business markets.

Given the problematic institutional infrastructure that may 
create a limited support to the GMP, firms should follow a more firm-level internal approach rather than external as their strategic look to obtain sustainable development. In emerging economies, people generally talk but do not act and this situation may generate implementation problems in the whole organizational processes. At this point, a suitable leadership style becomes crucial for the effective implementation of sustainability related issues that require organizational culture changes [16]. But we also believe that the relationship between the adoption of GMP and government policies and implementation leadership is more complex than a direct effect. Hence, the interaction effects of government policies and implementation leadership on GMP adoption should also be tested within the emerging economy context.

Therefore, this study has two aims: (1) to investigate the relative impact of government policies and implementation leadership that influence Turkish firms to adopt GMP, (2) to test the combined effects of government policies and implementation leadership on the way of fostering the adoption of GMP.

\section{THEORY AND HYPOTHESES}

The effects of government policies on firm performance have always been a critical issue in strategic management literature and especially, in institutional theory. In the specific institutional context, firm behaviors can be influenced by institutional forces [17]-[19]. Emerging economies display resource scarcities and a pervasive role of government institutions in economic activities [20]-[21]. According to Kearney [22], key institutional forces in emerging economies such as "government quality, the extent of state ownership, policies, regulations, norms, and the degree of financial development, impact upon the structures and behaviors of firms including their investments, strategies, financing, governance and growth". Institutional theory has been increasingly utilized to investigate the roles of different factors in green related issues. Menguc, Auh and Ozanne [23] suggest that government policies and regulations may play important roles in determining the degree to which firms may adopt GMP. Prior studies found that the government policies, laws and regulations that encouraged or even compelled firms to adopt GMP changed the behavior of firms in favor of green related implementations [4], [24]. The encouragements and impositions may occur in different forms such as penalties for pollution and toxic wastage and/or supportive policies (e.g., financial support, technical assistance, and green-related manpower training) that offer economic incentives.

In fact, the positive impact of government policies on the adoption of GMP is unquestionable in management research and this study does not aim to justify it. However, the types of resources and capabilities that firms acquire over time are related to the institutional environment surrounding them. In emerging economies, bureaucracy and government are too much involved into business and corruption level in these countries can be high. Moreover, lack of transparency and legal frameworks allowing opportunism, corruption and rent shifting dominate the whole market [25]-[26].

Under these conditions, firms can obtain several advantages to themselves through bribing, using relationships and networks with the government authorities and other unethical courses of action. Even if some of the rules and regulations may force the firms to adopt GMP, the firms may find some ways to override the legal framework in emerging economies. Given the weak institutional infrastructure and jurisdictional inefficiency in emerging economies, firms should adopt a more internal perspective as their strategic view to be able to follow GMP and increase their effects on firm competitiveness. Therefore, rather than the enforcements of government policies, strategic intent and leadership of a firm may be more effective for the implementation of GMP since senior management is responsible to formulate and initiate sustainability policies in organizations [27]. Many executives have demonstrated that sustainable development issues makes good business sense when environmental excellence has become a part of the strategy in their organizations.

"Going green" is not a new trend in management. It can only be achieved through the integration of the principles of sustainability with corporate strategic management processes, structures, cultures, systems and technologies, enabling both competitive and functional level strategies [28]. Therefore, an implementation leadership style becomes vitally important to achieve "going green" related objectives [16]. Strategic leadership that initiates the alignment of people to strategy facilitates the implementation of GMP in the firm.

Leadership is crucial "to study in organizational contexts since successful leadership can make a contribution towards survival of the firm, poor leadership may lead to organizational failure" [29]. In particular, green management literature suggests that leaders' vision, attitude and behavior are believed to represent best practices. While going green issues provide the organization to sustain competitive advantage, their implementation requires strategic and organizational changes [30]. There is empirical evidence for the importance of leadership in determining the strategic direction of the firm, facilitating the work flow and processes, and predicting the success of implementation efforts [31], [32]. Especially, transformational leaders who are capable of having profound and extraordinary effects on followers by the force of their personal abilities [33] have been shown to be "providing a sense of vision," "challenging the status quo" and "providing stimulation and inspiration". Moreover, a critical part of the leader's agenda is to formulate a vision, including the firm's strategic implementation of GMP. The leadership literature defines transformational leadership as the most suitable leadership style providing a strategic vision to the organization and its members and facilitating implementation of organizational practices [33]-[34].

Following the proposition of the leadership literature, this study uses transformational leadership dimensions to measure the impact of leadership behavior on the implementation of GMP. The adoption of a sustainable development strategy through GMP is influenced by the government policies and the strategic leadership of the organization. However, given the emerging economy characteristics of the business environment explained above, the internal firm-level factors can be more important than the external institutional forces on the adoption of GMP in firms. Therefore this study 
hypothesizes that:

$H_{1}$ : The effect of implementation leadership will be greater than that of government policies on the adoption of green management practices of firms within the emerging economy context.

Besides, since the government policies along with leadership styles of the organizations may create a synergetic effect on the adoption of GMP, it is also proposed that:

$\mathrm{H}_{2}$ : The combined effect of implementation leadership and government policies will be greatest on the adoption of green management practices of firms within the emerging economy context.

\section{METHODS}

\section{A. Sample and Data Collection}

Data for this research were obtained through a survey. The sample was selected from the databases of Turkish Chemical Society (TKD), Turkish Plastics Industrialists' Federation (PLASFED), The Association of Cosmetics and Cleaning Products Industrialists (KTSD), and The Association of Paint Industry (BOSAD). In Turkey, whilst the number of chemical manufacturers was 4221 , the number for the rubber and plastics was 12099 including the micro level firms and small to medium enterprises (SMEs) in 2014, according to the Social Security Institution [35]. However, the researchers could obtain data from the firms that were registered to an association only. So, a convenient sampling method was chosen in this study. The data collection process was quite tough. A single informant was used and the questionnaire was mailed to only one executive from each firm. As a result, a total of 153 useable questionnaires were obtained. The chemical and petrochemical industries have several sub-sectors including paint and coatings, fertilizer, detergent, cosmetics and personal care, plastics, rubber, and inorganic chemicals. Many chemical products are known to have toxic effects on human and environmental health and are considered dangerous. Therefore, it is imperative to foster the adoption of GMP in the industry. Moreover, according to the report of Investment Support and Promotion Agency of Turkey (ISPAT), "Turkey has ambitious 2023 targets for the chemical industry which include reaching USD 50 billion in chemical exports, thus capturing $0.79 \%$ share of the global chemicals market" [36]. These factors influenced the industry selection decision of the researchers.

\section{B. Measurement Instrument}

A self-administrated survey questionnaire that consists of three construct categories that are government policies, implementation (transformational) leadership, and GMP constructs was used as the measurement instrument. The questionnaire was consisted of a total number of 30 questions: 10 questions to measure the effects of government policies [24], [30], 12 questions for implementation leadership [37], 6 questions for GMP adoption [4], and 2 questions for the demographics (age and size). And the last question aimed to categorize the primary business activity of the firms. Some sample questions from the measurement instrument are as follows:

\section{1) Government policies}

Our national government enacts rules and regulations to foster GMP adoption.

Our national government has instituted a series of quality inspections and certification processes for GMP.

There are serious penalties for the firms that violate environmental rules in our industry.

\section{2) Implementation leadership}

Our executive establishes clear standards for implementation of GMP.

Our executive develops a plan to facilitate GMP implementation.

Our executive supports employee efforts to learn more about GMP.

Our executive reacts to critical issues regarding implementation of GMP.

\section{3) GMP adoption}

Our firm has been endeavoring to protect the environment.

Our firm has been endeavoring to eliminate detrimental factors in the workplace.

Our firm has been endeavoring to recycle and reuse the firm's products.

Responses to the items were recorded on a 5-point Likert-type scale and reliability and validity issues were assessed. The constructs that had alpha values equal to and above 0.70 were accepted as reliable constructs [38]. The reliability analyses show that all constructs possess satisfactory Cronbach's alpha values: government policies ( $\alpha=0.906)$, implementation leadership $(\alpha=0.893)$, and GMP adoption $(\alpha=0.884)$. Moreover, correlations between variables were examined to assess the presence of multicollinearity. Independence of the predictor variables is important since highly correlated independent variables can predict each other and may cause problems with multicollinearity which influence the accuracy of the regression analysis negatively [39]. So, inter-correlations between variables were examined and moderate levels of correlations that were below 0.80 did not seem to create multicollinearity problem [39].

\section{Analyses}

Multiple regression analyses were used to analyze the data. A four-step hierarchical analysis was conducted. In hierarchical regression method, each set of independent variables is entered into separate blocks for analysis and the incremental changes of the $\mathrm{R}^{2}$ statistic and the $\beta$ coefficients are calculated. The control variables (age and size) were first entered and then government policies (GP) variable was entered in the second step. Having entered the implementation leadership (IL) variable in the third step, the interaction term of GP and IL (GP x IL) was entered in the fourth step to predict the GMP adoption (Table I).

\section{Results}

The results of regression analyses are given in Table 1 . In Model 1, just the control variables, including firm age and firm size which explained no significant share of the variance in GMP adoption were entered. In Model 2, GP was added and a positively significant relationship between GP and 
GMP adoption was found $\left(\beta=0.258^{* *}, p<0.01\right)$. The addition of GP has explained $15.5 \%\left[\left(R^{2}=0.155\right) ;(F=2.369\right.$, $p<0.01)]$ variation in the model. IL was entered in Model 3, and a significant effect on GMP adoption was also observed $\left(\beta=0.302^{*}, p<0.05\right)$. Moreover, the explanation in variation has increased to $31.2 \%\left[\left(R^{2}=0.312\right) ;(F=2.682, p<0.05)\right]$. Whilst the entrance of GP has provided a contribution of $11.9 \%\left(\Delta R^{2}=0.119\right)$, IL has contributed with $15.7 \%\left(\Delta R^{2}=\right.$ $0.157)$ to the variation of the model. Given the higher $\beta$ value and a higher contribution to the variance explanation, IL's impact on GMP adoption was observed to be greater. Therefore, $\mathrm{H} 1$ is supported.

In Model 4, the joint effect of GP and IL was significant on GMP adoption with the greatest $\beta$ value $\left(\beta=0.564^{*}, p<0.05\right)$. $\mathrm{R}^{2}$ change was also significant and the addition of the joint effect of GP and IL has provided the highest contribution to the explanation power of the model $\left(\Delta R^{2}=0.191\right)$. Hence, based on the $\beta$ coefficients and significant $R^{2}$ changes, $\mathrm{H}_{2}$ was also confirmed.

\section{TABLE I: THE RESULTS OF REGRESSION ANALYSES}

\begin{tabular}{lcccc}
\hline \hline $\begin{array}{l}\text { DV: GMP } \\
\text { Adoption }\end{array}$ & & & & \\
Predictors & Model 1 & Model 2 & Model 3 & Model 4 \\
\hline Firm size & 0.021 & 0.018 & 0.019 & 0.012 \\
Firm age & 0.016 & -0.004 & 0.003 & 0.026 \\
GP & & $0.258^{* *}$ & & \\
IL & & & $0.302^{*}$ & \\
GP X IL & & & & $0.564^{*}$ \\
& & & & \\
$R^{2}$ & 0.036 & 0.155 & 0.312 & 0.503 \\
$\Delta R^{2}$ & - & 0.119 & 0.157 & 0.191 \\
$F$ & 1.045 & $2.369 * *$ & $2.682^{*}$ & $3.005^{*}$ \\
\hline \hline
\end{tabular}

DV: Dependent Variable

$N=153$

${ }^{*} p<0.05 ; * * p<0.01$ (two-tailed)

\section{DISCUSSION AND CONCLUSION}

This research seeks to investigate the relative importance of government policies and implementation leadership on the adoption of green management practices of firms. The findings revealed that the impact of implementation leadership on green management practices was greater than that of government policies. One explanation to this result is that institutional and legal barriers can be somehow and somewhat overridden to some extent by the Turkish firms on the way of adopting green management practices. However, an effective leadership which considers "going green" as a competitive strategy and integrates this notion into the corporate strategic plans of the firm can facilitate the adoption of green related applications. In this sense, the impact of leadership on the way of implementing the green related issues can be more than that of governmental policies. Clearly, when the two variables act together, firms can adopt green management practices much easier and effectively.

\section{REFERENCES}

[1] The UN Report, "Development agenda of Turkey for Post-2015," National Consultations Report, 2013.

[2] The Economist Intelligence Unit. (2012). The green city index. [Online]. Available: http://www.siemens.com/entry/cc/features/greencityindex_internation al/all/en/pdf/gci_report_summary.pdf
[3] The CDP Report. (2013). Sector insights: What is driving climate change action in the world's largest companies? [Online]. Available: https://www.cdp.net/cdpresults/cdp-global-500-climate-change-report -2013.pdf

[4] J. Yang, F. Zhang, X. Jiang, and W. Sun, "Strategic flexibility, green management, and firm competitiveness in an emerging economy," Technological Forecasting \& Social Change, $(\mathrm{xxx}), 2015$.

[5] J. Aguilera-Caracuel, J. A. Aragón-Correa, N. E. Hurtado-Torres, and A. M. Rugman, "The effects of institutional distance and headquarters' financial performance on the generation of environmental standards in multinational companies," Journal of Business Ethics, vol. 105, no. 4, pp. 461-474, 2012.

[6] G. Jackson and A. Apostolakou, "Corporate social responsibility in Western Europe: An institutional mirror or substitute?" Journal of Business Ethics, vol. 94, no. 3, pp. 371-394, 2010.

[7] I. Ioannou and G. Serafeim, "The impact of corporate social responsibility on investment recommendations: Analysts' perceptions and shifting institutional logics," Strategic Management Journal, vol. 36, no. 7, pp. 1053-1081, 2015.

[8] P. Ambec and S. Lanoie, "Does it pay to be green? A systematic overview," Academy of Management Perspectives, vol. 22, no. 4, pp. 45-62, 2008

[9] W. Q. Judge and D. Elenkov, "Organizational capacity for change and environmental performance: An empirical assessment of Bulgarian firms," Journal of Business Research, vol. 58, no. 7, pp. 893-901, 2005.

[10] T. Cavusgil, P. N. Ghauri, and A. A. Akcal, Doing Business in Emerging Markets, 2nd ed. London, UK: Sage Publications, 2013.

[11] E. Tatoglu and M. Demirbag, "Transition in the age of anxiety: The Turkish case," Journal of Management Development, vol. 27, no. 7, pp. 653-659, 2008.

[12] D. Matten and J. Moon, "Implicit and explicit CSR: A conceptual framework for a comparative understanding of corporate social responsibility," Academy of Management Review, vol. 33, no. 2, pp 404-424, 2008.

[13] IMF World Economic Outlook. (2012). World Economic Outlook Database. [Online]. Available: www.imf.org/external/country/TUR/index.htm. IMF World Economic Outlook. (2014). World Economic Outlook Database. [Online]. Available: ww.imf.org/external/country/TUR/index.htm.

[14] Price Waterhouse Coopers (PwC) Report. (2015). The World in 2050: Will the shift in global economic power continue? [Online]. Available: www.pwc.com/gx/en/issues/the-economy/assets/world-in-2050-febru ary-2015.pdf

[15] C. A. O'Reilly, D. F. Caldwell, J. A. Chatman, M. Lapiz, and W. Self, "How leadership matters: The effects of leaders' alignment on strategy implementation," The Leadership Quarterly, vol. 21, no. 1, pp. 104-113, 2010.

[16] D. Jamali and B. Neville, "Convergence versus divergence of CSR in developing countries: An embedded multi-layered institutional lens," Journal of Business Ethics, vol. 102, no. 4, pp. 599-621, 2011.

[17] J. L. Campbell, "Why would corporations behave in socially responsible ways? An institutional theory of corporate social responsibility," Academy of Management Review, vol. 32, no. 3, pp. 946-967, 2007.

[18] P. J. DiMaggio and W. W. Powell, The New Institutionalism in Organizational Analysis, University of Chicago Press, Chicago, 1991.

[19] J. Austin, J. 'The boundaries of business: The developing country difference," Harvard Business Review, vol. 69, no. 4, pp. 134-136, July-August, 1991

[20] M. Wright, I. Filatotchev, R. Hoskisson, and M. Peng, "Guest editors' introduction: Strategy research in emerging economies: Challenging the conventional wisdom," Journal of Management Studies, vol. 42, no. 1, pp. 1-33, 2005.

[21] C. Kearney, "Emerging markets research: Trends, issues and future directions," Emerging Markets Review, vol. 13, no. 2, pp. 159-183, 2012.

[22] B. Menguc, S. Auh, and L. Ozanne "The interactive effect of internal and external factors on a proactive environmental strategy and its influence on a firm's performance," Journal of Business Ethics, vol. 94, no. 2, pp. 279-298, 2010.

[23] O. R. Malik and M. Kotabe, "Dynamic capabilities, government policies, and performance in firms from emerging economies: Evidence from India and Pakistan," Journal of Management Studies, vol. 46, no. 3, pp. 421-450, 2009.

[24] R. E. Hoskisson, L. Eden, C. M. Lau, and M. Wright, "Strategies in emerging economies," Academy of Management Journal, vol. 43, no. 3 , pp. 249-267, 2000. 
[25] F. Nowak-Lehmann, D. Herzer, I. Martinez-Zarzoso, and S. Vollmer, "The impact of customs union between Turkey and the EU on Turkey's exports to the EU," Journal of Common Market Studies, vol. 45, no. 3, pp. 719-743, 2007.

[26] E. G. Olson, "Not by technology alone: Sustaining winning strategies," Journal of Business Strategy, vol. 27, no. 4, pp. 33-42, 2006.

[27] H. Borland, "Conceptualizing global strategic sustainability and corporate transformational change," International Marketing Review, vol. 26, nos. 4/5, pp. 554-572, 2009.

[28] M. Ozbilgin, "Leadership in Turkey: Towards an evidence based and contextual approach," in Leadership Development in the Middle East, B. Metcalfe and F. Mimouni, Eds. Edward Elgar Press: New York and Cheltenham, 2011.

[29] C. Y. Lin and Y. H. Ho, "Determinants of green practice adoption for logistics companies in China," Journal of Business Ethics, vol. 98, no. 1, pp. 67-83, 2011.

[30] D. A. Waldman, G. G. Ramirez, R. J. House, and P. Puranam, "Does leadership matter? CEO leadership attributes and profitability under conditions of perceived environmental uncertainty," Academy of Management Journal, vol. 44, no. 1, pp. 134-143, 2001.

[31] D. Vera and M. Crossan, "Strategic leadership and organizational learning," Academy of Management Review, vol. 29, no. 2, pp. 222-240, 2004

[32] E. Rafferty and M. A. Griffin, "Dimensions of transformational leadership: Conceptual and empirical extensions," The Leadership Quarterly, vol. 15, no. 3, pp. 329-354, 2004.

[33] B. Michaelis, R. Stegmaier, and K. Sonntag, "Shedding light on followers' innovation implementation behavior: The role of transformational leadership, commitment to change, and climate for initiative," Journal of Managerial Psychology, vol. 25, no. 4, pp. 408-429, 2010.

[34] SGK, Social Security Institution. (2014). [Online]. Available: www.sgk.gov.tr

[35] ISPAT, Investment Support and Promotion Agency of Turkey. The Chemicals Industry in Turkey. [Online]. Available:
http://www.invest.gov.tr/en-US/infocenter/publications/Documents/C HEMICALS.INDUSTRY.pdf

[36] A. A. Gregory, G. M. Ehrhart, and L. R. Farahnak, "The implementation leadership scale (ILS): Development of a brief measure of unit level implementation leadership," Implementation Science, vol. 9, no. 1, pp. 45-55, 2014.

[37] J. Nunnally and I. Bernstein, Psychometric Theory, New York: McGraw Hill, 1994.

[38] M. Saunders, P. Lewis, and A. Thornhill, Research Methods for Business Students, 4th ed. Essex, UK: Pearson Education, 2007.

Rifat Kamasak has been working as an associate professor of management at Yeditepe University, Faculty of Commerce, Istanbul since March 2006. He has graduated from the University of Istanbul, Faculty of Economics and completed his MA in marketing and MA in management degrees from Middlesex University and the University of Durham, UK. He also holds separate $\mathrm{PhD}$ degrees in management and organization and strategic management from the University of Istanbul and University of Exeter, UK. His primary interest areas are business strategy, resource-based view of strategic management, organization theory and innovation.

Ugur Yozgat is a communication and electronics engineer, received his BA, $\mathrm{MA}$ and $\mathrm{PhD}$ degrees from Istanbul Technical University and Marmara University, Istanbul respectively. He still works as a full professor in Marmara University, Faculty of Business. His primary interest areas are knowledge management, research methods and innovation.

Meltem Yavuz has graduated from Yeditepe University, Faculty of Commerce, Istanbul and received her master's degree in transportation and logistics management from Istanbul University. Currently, she studies her $\mathrm{PhD}$ in management degree in Marmara University, Istanbul. 